\title{
La memoria oficial de la Independencia mexicana: el discurso del Gobierno Federal durante las conmemoraciones bicentenarias del 2010
}

\section{The official memory of mexican Independence: the speech of the Federal Government during the bicentenary commemorations of 2010}

\author{
INMACULADA VERDÚ SÁNCHEZ* \\ Universidad de Valencia, España \\ Inmaculada.verdu@uv.es \\ https://doi.org/10.36105/iut.2021n34.06
}

Recibido: $19 / 11 / 2021$

Aceptado: 31/12/2021

\section{RESUMEN}

El presente artículo tiene como objeto de estudio un proceso fundamental de las sociedades contemporáneas como es el uso que de la memoria histórica se realiza para la afirmación de la identidad nacional. El propósito es analizar los diferentes discursos del pasado impulsados por parte del ejecutivo federal de México durante la celebración del Bicentenario de la Independencia en 2010, con el propósito de conocer si las diversas iniciativas conmemorativas que se desarrollaron consiguieron actualizar los lazos de pertenencia a la nación de los mexicanos y mexicanas.

* Este trabajo forma parte del proyecto de investigación "Las barricadas del recuerdo. Historia y memoria de la era de las revoluciones en España e Hispanoamérica, 1776-1848", PID2020-120048GB-I00, financiado por el Ministerio de Ciencia e Innovación y está inscrito en el Programa de Formación del Profesorado Universitario, FPU18/03864. 
Palabras clave:

bicentenario, Independencia, memoria oficial, discurso oficial, identidad nacional.

Abstract:

The purpose of this paper is to study a fundamental process in contemporary societies: the use of historical memory for the affirmation of national identity. The objective is to analyze the different discourses of the past promoted by the Mexican federal executive during the celebration of the Bicentennial of Independence in 2010, to know if the various commemorative initiatives managed to update the ties of belonging to the nation of Mexicans.

Keywords:

Bicentennial, independence, official memory, official speech, national identity.

\section{La memoria oficial como transmisora de la identidad nacional}

El presente trabajo tiene como objeto de estudio las políticas de conmemoración desarrolladas en México con motivo del Bicentenario de la Independencia en 2010, por cuanto suponen una excelente oportunidad para indagar en la formación de una memoria oficial por parte del Estado y el uso que de ella se realiza para la afirmación de la identidad nacional. Esto se debe a que el proceso histórico de la Independencia mexicana es el pasado referencial a partir del cual se ha construido e inventado una determinada idea de nación cultural e históricamente homogénea, la cual se vio interpelada con la llegada del Bicentenario.

El caso mexicano presenta, además, una particularidad con respecto al resto de países iberoamericanos que también celebraron su Bicentenario por esas fechas: en 2010 se celebraron no sólo los doscientos años del inicio del proceso de Independencia, sino también los cien años del inicio de la Revolución mexicana, otro de los grandes hitos históricos de la nación. De ahí que el 2010 fuera anunciado en México como el "Año de la Patria", pues las conmemoraciones de ese año tuvieron un sentido especial al presentarse como el momento idóneo para que la sociedad mexicana reflexionara sobre el pasado, presente y futuro de la nación. ${ }^{1}$

El objetivo, pues, es analizar los diferentes discursos políticos y de nación que, en el contexto de la celebración del Bicentenario de la Independencia mexicana, fueron elaborados por el ejecutivo federal. Con ello, se trata de abordar la memoria oficial de la Independencia mexicana que se impulsó durante las celebraciones bicentenarias. En este punto, es necesario realizar una aclaración terminológica, y es que la profusión y confusión de términos es enorme en los llamados

1 MAYER, A. (coord.), México en tres momentos: 1810-1910-2010. Hacia la conmemoración del bicentenario de la Independencia y del centenario de la Revolución Mexicana. Retos y perspectivas, 2 vol., UNAM, 2007. 
"estudios de la memoria". En no pocas ocasiones se utiliza indistintamente "memoria colectiva", "memoria histórica", "memoria nacional" y "memoria cultural". No es mi intención entrar a debatir cuál es la idoneidad de cada término, pero he preferido escoger el de "memoria oficial" para referirme a aquella memoria que el Estado o las élites políticas tratan de transmitir a la sociedad a través de las conmemoraciones para sociabilizarla en una identidad nacional. El abordaje de este tipo de memoria es muy interesante pues, como bien señaló Paloma Aguilar, es aquella que más visibilidad adquiere en el espacio público, la que se refleja en los monumentos y conmemoraciones, y suele ser la "dominante". 2

En lo que respecta a las fuentes primarias empleadas para alcanzar el propósito de este trabajo, se ha examinado un material muy diverso que puede clasificarse en tres bloques. En primer lugar, para analizar el discurso oficial difundido por el ejecutivo mexicano se ha acudido al canal de YouTube de la Presidencia de Felipe Calderón Hinojosa. Se trata de un canal creado por el propio gobierno federal, cuya autenticidad está verificada por el sitio web, donde se recopilan todos los actos e intervenciones realizadas por el presidente durante su mandato. Y cómo no, en él se recogen también todos aquellos relacionados con la conmemoración del Bicentenario de la Independencia. Examinar este tipo de documentos audiovisuales es especialmente interesante para el objeto de estudio de esta investigación, ya que a través de su visionado se puede analizar la puesta en escena de la simbología y el discurso que nutre el relato oficial de la Independencia mexicana. A la vez que es oportuno, en la medida en que el gobierno federal hizo un extraordinario uso de los medios de comunicación y las tecnologías durante la celebración del Bicentenario.

En segundo lugar, y en relación con el discurso oficial del Bicentenario de la Independencia, también es interesante abordar aquellas obras dedicadas a las conmemoraciones bicentenarias que fueron publicadas por la Presidencia de la República junto con otras instituciones gubernamentales como son la Secretaría de Educación Pública, el Consejo Nacional para la Cultura y las Artes y el Instituto Nacional de Estudios Históricos de las Revoluciones de México. Este tipo de iniciativas conmemorativas son muy atractivas pues tienen vocación de servir tanto de difusión de la historia mexicana como de reflejo del modo en que la nación celebró una de sus grandes efemérides. Así pues, en cuanto que fueron impulsadas por gobierno federal con sendos propósitos, permiten acercarse al sentido que este deseaba dar a las celebraciones.

En último lugar, se ha trabajado también la prensa de la época, concretamente una serie de publicaciones realizadas por cuatro periódicos mexicanos de tirada nacional, La Jornada, El Informador, Excélsior y El Universal, pues en ellas se aborda el desarrollo de las diferentes iniciativas conmemorativas organizadas con motivo del Bicentenario de la Independencia. No obstante, se han obviado las noticias que tan solo se hacen eco de los festejos, así como aquellos artículos de opinión que no realizan una crítica seria de las celebraciones, sino

$\overline{2}$ Agullar, P., Políticas de la memoria y memorias de la política, Madrid, Alianza, 2008, pp. 57-58. 
que únicamente las emplean como pretexto para criticar al gobierno federal. Por el contrario, se han seleccionado aquellas noticias que abordan el análisis y la crítica de las cuestiones que fueron más ampliamente discutidas durante las celebraciones, como fue la falta de contenido histórico que las caracterizó, entre otras muchas.

Por otra parte, cabe señalar cuáles son las preguntas que orientan y motivan este trabajo. En primer lugar, hay que mencionar que el partido del gobierno al que le tocó conmemorar en 2010 la Independencia fue el Partido Acción Nacional (PAN). Este tiene una concepción historiográfica radicalmente opuesta a la construida y mantenida por el Partido Revolucionario Institucional (PRI); ${ }^{3}$ $\mathrm{y}$, por lo tanto, se encontraba al frente de un país donde la inmensa mayoría de la población había aprendido la historia oficial de México, pues era la impartida en las escuelas públicas durante los setenta años de régimen priista. Una historia patria liberal basada en una serie de referentes simbólicos que podrían resumirse en:

exaltación del mundo prehispánico y postergación de la época colonial. Tres grandes momentos: Independencia, Reforma y Revolución, entrelazados por las luchas populares por la libertad. Héroes: Moctezuma y Cuauhtémoc, los resistentes; Hidalgo y Morelos, coautores de la Independencia; los gigantes de la Reforma encabezados por Benito Juárez, defensores todos ellos de la nación. Culmina el proceso con la Revolución y sus héroes: Madero, Carranza y Zapata, fundamentalmente, pues Villa como que no arraiga del todo por su original bandolerismo. Personajes problemáticos: Iturbide, Díaz y los hermanos Flores Magón, sobre los que pesa todavía la acusación de filibusterismo. ${ }^{4}$

Con la derrota del PRI, diversos sectores de la sociedad vieron que era posible y urgente hacer una revisión de la historia tradicional, ya que durante décadas había legitimado la hegemonía del régimen priista en el poder. Durante ese tiempo, los personajes y acontecimientos históricos de la historia oficial fueron convertidos en estatuas, monumentos y plazas conmemorativas, "que permitían

El escenario político mexicano del siglo xx se caracterizó por la hegemonía incontestable del PRI, pues el partido estuvo al frente del país desde 1929 al 2000. De ahí que algunos politólogos como Joy Langston consideren al régimen priista como uno de los regímenes políticos autoritarios más centralizados. Por su parte, el PAN, fundado en 1939, se erigió como el principal partido opositor, aglutinador de las posturas conservadoras. Ambos partidos representarían, por tanto, la tradicional división de "izquierda-derecha". Durante el periodo de supremacía priista, la derecha fue considerada como una alternativa política ilegítima. Sin embargo, todo cambió cuando en el año 2000, el PAN ganó las elecciones presidenciales y, con ello, culminó la larga transición política de México hacia la democracia. Para ampliar más información sobre la historia del PAN en la oposición y su ascensión al poder, pueden consultarse: Hernández, T., Tras las huellas de la derecha. El Partido Acción Nacional, 1939-2000, México, Fondo de Cultura Económica, 2021; LoAezA, S., Acción Nacional. El apetito y las responsabilidades del triunfo, México, El Colegio de México, 2010. En cuanto a la trayectoria política del PRI y su declive: LAngston, J., De la hegemonía a la ignominia: el PRI de México, México, Centro de Investigación y Docencia Económicas, 2019; LANGSTon, J., "El dinosaurio que no murió: el PRI de México", en Servín, E. (eds.), Del nacionalismo al neoliberalismo, 1949-1994, México, Fondo de Cultura Económica, 2011.

4 Medina PeÑa, L., "Las dos historias patrias", en "Bicentenario de la Independencia ¿Qué celebramos?", Nexos, septiembre 2009, Recuperado de: https://www.nexos.com.mx/?p=13271 
su fijación en la memoria nacional". ${ }^{5}$ Esta apropiación ideológica del pasado nacional se dio especialmente en el caso de la Revolución mexicana, puesto que los líderes del PRI vieron en ella el instrumento perfecto para forjar un nacionalismo que unificara el país, a la vez que legitimar su proyecto político, económico y social. ${ }^{6}$

En México, por lo tanto, la historia no solo fue una herramienta para elaborar un pasado común que sirviera a la construcción de la identidad nacional, sino que también tuvo un lugar privilegiado en la justificación del sistema político, en la medida que el PRI legitimó su proyecto nacional en la Revolución mexicana en vez de en la democracia participativa. Esta falta de legalidad electoral del régimen priista es lo que explica, precisamente, la importancia que tuvo establecer una versión oficial con la que alegar su legitimidad histórica. Así pues, el PRI se adueñó de la historia nacional, en especial del legado de la Revolución, y presentó al régimen como el único guardián de las tradiciones revolucionarias en México. ${ }^{7}$

No es de extrañar, por tanto, que muchas voces señalaran que el gobierno federal no se sentía cómodo con la versión de la historia oficial que durante setenta años legitimó al PRI en el poder y sustentó su nacionalismo revolucionario, debido a que el PAN es heredero de aquellos que se opusieron al proyecto político e ideológico de la Revolución mexicana. ${ }^{8}$ A todo ello hay que sumar el hecho de que la posición historiográfica defendida por el partido del gobierno federal no se adecuaba al objetivo natural de las celebraciones, pues los ideólogos del partido interpretaron la historia de México como una sucesión de movimientos violentos, especialmente la Revolución mexicana, que trajo para el país más consecuencias negativas que positivas. De la misma forma que los héroes nacionales como Juárez, Guerrero, Villa o Zapata eran vistos por los conservadores como demagogos, ignorantes y ávidos de poder. ${ }^{9}$

Por todo ello, la primera pregunta que surge es si finalmente el PAN acabó ofreciendo un relato de la Independencia diferente, más acorde con su concepción historiográfica e ideológica, y con el proyecto de nación conservador que defiende; o si finalmente se limitó a reproducir la memoria oficial que el PRI sostuvo durante los setenta años que estuvo en el poder. Para poder responder a esta pregunta es necesario abordar las políticas de memoria que el gobierno federal llevó a cabo durante el Bicentenario de la Independencia mexicana. Se trata, por tanto,

5 Ríos GoRdillo, C.A., "La memoria asediada: la disputa por el presente en la conmemoración del bicentenario", Secuencia, núm. 87, 2013, pp. 189-190.

6 Carrillo Reveles, V., "Graffiteando la historia: la conmemoración del Bicentenario de la Independencia de México", Revista CCHEHS, núm. 2, 2010, p. 36.

7 LoAeza, S., "La historia, la historia patria y la formación de un nuevo consenso nacional" en PANI, E. y Rodríguez, A. (coord.), Centenarios. Conmemoraciones e historia oficial, México, El Colegio de México, Centro de Estudios Históricos, 2012, pp. 393-394.

8 Granados, L.F., "Independencia sin insurgentes. El bicentenario y la historiografía de nuestros días", Desacatos, núm. 34, 2010, p. 12.

9 Garciadiego, J., "La política de la historia: las conmemoraciones de 2010", en Pani, E. y RodríGuez, A. (coord.), Centenarios. Conmemoraciones e historia oficial, México, El Colegio de México, Centro de Estudios Históricos, 2012, p. 359. 
de analizar el significado de las iniciativas conmemorativas oficiales; pero también el propio discurso de nación que el presidente Felipe Calderón impulsó con motivo de las celebraciones, pues en este se repitió infinidad de veces que el Bicentenario tenía como objetivo conseguir el "orgullo", la "unidad" y la "reconciliación" de los mexicanos. De ahí surge la segunda de las preguntas: si realmente este discurso tuvo su contrapartida en las diversas iniciativas conmemorativas que el ejecutivo federal puso en marcha. Si estas tuvieron realmente una utilidad pública y consiguieron el objetivo propuesto por Felipe Calderón: actualizar los lazos de pertenencia a la nación de los mexicanos y mexicanas, intención última de las conmemoraciones nacionales, al fin y al cabo.

\section{Las iniciativas conmemorativas del ejecutivo federal}

El ejecutivo federal fue el encargado de encabezar las conmemoraciones del Bicentenario de la Independencia en 2010, igual que lo había hecho en las celebraciones centenarias de 1910 y 1921 . El 10 de febrero de ese año, el entonces presidente de la República mexicana, Felipe Calderón, presentó el "programa de actividades del Bicentenario de la Independencia y Centenario de la Revolución mexicana". En lo que respecta a las iniciativas conmemorativas que conformaron este programa de actividades, consistieron en una gran variedad de proyectos de todo tipo. Un análisis de todos ellos sería una tarea imposible de acometer para las dimensiones de este estudio. Por ello, sólo se abordan aquellas que por su importancia y significado se han considerado más relevantes.

En primer lugar, destaca la presentación del propio programa de festejos, ${ }^{10}$ pues tuvo una gran intencionalidad política. En este primer evento ya se pudo observar que durante la coyuntura conmemorativa se iba a desplegar una gran retórica nacionalista. Para comenzar, el discurso difundido por el mandatario trató de inflamar el espíritu nacional de los mexicanos y mexicanas con continuas referencias a su necesaria conciliación y unión en torno a "los intereses superiores de la nación", más allá de las diferencias existentes. ${ }^{11}$ Este discurso nacional y nacionalista, con continuas referencias a la unidad del pueblo mexicano tuvo, además, el mejor escenario posible, pues el ejecutivo federal decidió convocar la presentación del programa el 10 de febrero precisamente porque era una fecha que simbolizaba a la perfección la idea que Calderón estaba tratando de transmitir a los mexicanos y mexicanas. Ese mismo día en 1821:

tuvo lugar un evento crucial que permitió a México alcanzar su independencia. Se encontraron en Acatempan, Guerrero, jefe del ejército insurgente del sur, e Iturbide, que comandaba a las fuerzas realistas, y se encontraron para hacer la paz. Guerrero

10 (Presidencia Felipe Calderón Hinojosa). (10 de febrero de 2010). Programa de actividades del Bicentenario de la Independencia y del Centenario de la Revolución [Archivo de video]. Recuperado de: https://www. youtube.com/watch? $=\mathrm{uzFM} 7 \mathrm{xdM} 2 \mathrm{yU} \& \mathrm{t}=5 \mathrm{~s}$

11 Melgar, I. (11 de febrero de 2010). Calderón pide superar las diferencias políticas. Excélsior, p. 4; Ramos, J. (11 de febrero de 2010). Convocan a festejar en unidad. El Universal, p. 22; Calderón apela a la hermandad. (11 de febrero de 2010). El Informador, p. 3-A. 
e Iturbide habían sido enemigos acérrimos. Sin embargo, en ese momento ambos procuraban la independencia de nuestra nación, sellaron su alianza con un abrazo y de esta reconciliación nació el ejército trigarante que consumó la Independencia nacional. ${ }^{12}$

Es interesante que el mandatario escogiera mencionar ese hecho histórico durante la presentación del programa de actividades conmemorativas, puesto que es un suceso que no pertenece a la etapa de la insurgencia, sino a la etapa final del proceso emancipador, cuando este se "consuma". ${ }^{13}$ Recordemos que en 2010 se estaba celebrando el Bicentenario del Inicio de la Independencia y no su consumación (la cual ha sido conmemorada en 2021). No obstante, el abrazo de Acatempan es un episodio de la historia nacional que sí concuerda con la concepción historiográfica del PAN: es el momento en que Vicente Guerrero y el general realista Agustín de Iturbide sellan la alianza que los llevará a conseguir la independencia de México. Es, por tanto, un acontecimiento en el que Iturbide tiene un gran protagonismo y peso, un personaje cuya memoria ha sido borrada del relato oficial de la Independencia por ser considerado por los liberales un traidor a la patria. Los conservadores, en cambio, lo ven como el auténtico "Libertador" de la patria mexicana, por lo que su memoria merece ser reivindicada y recuperada. En definitiva, puede interpretarse la mención al abrazo de Acatempan como un ligero distanciamiento del gobierno federal de la memoria oficial sostenida por el PRI durante décadas en el poder.

Por otra parte, también llama la atención la referencia al abrazo de Acatempan porque justo un mes antes, el entonces coordinador encargado de la comisión nacional de festejos, Manuel López Villalpando, había dimitido. Un historiador que había sido puesto en entredicho para ocupar ese cargo, tanto por su relación con Felipe Calderón como por su manera de concebir la historia, y cuyos trabajos como "El Abrazo de Acatempan" habían sido especialmente criticados por su excesivo presentismo y "populismo historiográfico". ${ }^{14}$ Pues bien, el presidente lo que hizo en su discurso de presentación del programa conmemorativo no fue otra cosa que repetir la idea final de esta obra, esto es la necesidad de que en el país se volviera a dar un nuevo "abrazo", con el que los ciudadanos dejaran de lado

12 (Presidencia Felipe Calderón Hinojosa). (10 de febrero de 2010). Programa de actividades del Bicentenario de la Independencia y del Centenario de la Revolución [Archivo de video]. Recuperado de: https://www. youtube.com/watch? $=\mathrm{uzFM} 7 \mathrm{xdM} 2 \mathrm{yU} \& \mathrm{t}=5 \mathrm{~s}$

13 La historiografía ha señalado que el término consumación no es exacto para referirse a lo acontecido en 1821, dado que supone ligar el pronunciamiento encabezado por Agustín de Iturbide con la insurrección de Hidalgo, cuando estamos hablando de movimientos en parte distintos. Aun así, sigue utilizándose el concepto porque resulta operativo en términos discursivos. Sobre el particular Moreno, R., "Nuestras ideas sobre la consumación. Recorrido historiográfico sobre el proceso de la consumación de la independencia de México", en Terán, M. y GAYOL, V. (eds.), La corona rota: identidades y representaciones en las independencias iberoamericanas, Castelló de la Plana, Universitat Jaume I, 2010. Un ejemplo reciente en IBARRA, A.C., OrTIZ, J. y Tecuanhuey, A. (coord.), La consumación de la independencia. Nuevas interpretaciones, Xalapa, Universidad Veracruzana, El Colegio de Michoacán, UNAM, 2021.

14 Breña, R., "Historia compleja, festejo simple", en "Bicentenario de la Independencia ¿Qué celebramos?", Nexos, septiembre 2009, Recuperado de: https://www.nexos.com.mx/?p=13272 
sus discrepancias en pro de la nación mexicana. ${ }^{15}$ Vemos, pues, claramente la influencia de Villalpando sobre Felipe Calderón, así como que, desde la misma presentación del programa de actividades, el ejecutivo federal iba a usar la historia como recurso político para legitimar el proyecto de nación que había diseñado.

En segundo lugar, del programa conmemorativo nacional también destacó, por su alcance y difusión, el espectáculo audiovisual "200 años orgullosamente mexicanos"16 que recorrió los 32 estados de la República mexicana durante ocho meses, en el que se documentaban los principales acontecimientos históricos del país. Lo curioso de esta iniciativa es que, si bien el propio título hace referencia a los dos siglos de existencia independiente de México, el espectáculo no se limita a realizar solo un repaso de esos doscientos años de historia, sino que comienza con imágenes que evocan a las civilizaciones mesoamericanas que habitaron el territorio en el 1200 a.C., como las cabezas Olmecas. Continúa el recorrido por el pasado del territorio mexicano y siguen apareciendo en la pantalla imágenes que aluden a las civilizaciones prehispánicas hasta llegar a 1325, momento en que supuestamente se fundó la ciudad de México-Tenochtitlan. Después de esa imagen, la pantalla oscurece y aparecen tres carabelas surcando el mar, todo ello envuelto de una música y ambientación tenebrosa. Y tras esta aparición, comienzan las escenas de lucha entre españoles e indígenas. No es difícil entender la intencionalidad de presentar la asociación simbólica entre los años de oscuridad, guerra y destrucción con la llegada de los colonizadores españoles.

Las imágenes que siguen a los enfrentamientos vuelven a ser alegres y muestran a los espectadores cómo era la vida colonial de la Nueva España. Es esta una interpretación igualmente idílica del pasado no siempre correspondida con la realidad histórica. Pero a partir de ahí, todo se vuelve oscuro nuevamente y surge en la pantalla un texto que reza "De una vez y para lo venido, debéis saber que habéis nacido para callar y obedecer y no para discutir y opinar en los altos asuntos del gobierno". Una frase que el virrey de la Nueva España, el Marqués de Croix, escribió en 1767 y que pretende relacionar la miseria y explotación de los indígenas con la autoridad ejercida por los españoles.

$\overline{15}$ La alusión al abrazo de Acatempan puede interpretarse como un ejemplo de la memoria reconciliatoria de la que habla Camila Perochena, pues las referencias continuas a la necesaria unidad del pueblo mexicano fueron parte la estrategia del gobierno federal de tratar de resolver el conflicto político en el país: Perochena, C., "Tiempo, historia y política. Una reflexión comparativa sobre las conmemoraciones bicentenarias en México y Argentina", História da Historiografia, núm. 27, 2018, pp. 142-172.

16 GOBIERNO FEDERAL, México 2010: crónica y memoria de las conmemoraciones del Bicentenario del Inicio de la Independencia Nacional y el Centenario del Inicio de la Revolución Mexicana, México, Presidencia de la República, Secretaría de Educación Pública, Consejo Nacional para la Cultura y las Artes, Instituto Nacional de Estudios Históricos de las Revoluciones de México, 2010, pp. 83-88; GOBIERNO FEDERAL, Reporte de las principales actividades conmemorativas con motivo del Bicentenario del inicio de la Independencia Nacional y del centenario del inicio de la Revolución mexicana, México, Secretaría de Educación Pública, Instituto Nacional de Estudios Históricos de las Revoluciones de México, Coordinación Ejecutiva Nacional de las Conmemoraciones, 2010, p. 127; (Presidencia Felipe Calderón Hinojosa). (6 de mayo de 2010). Video proyectado. 200 años de ser orgullosamente mexicanos [Archivo de video]. Recuperado de: https://www.youtube.com/watch?v=11J99CZt3cI\&t=1277s 
Le siguen a estas palabras de nuevo un ambiente tenebroso, comienzan a repicar las campanas y aparecen manos alzadas y armadas de una muchedumbre que grita. Tras esta escena comienzan a surgir en la pantalla referencias a acontecimientos y personajes históricos conocidos: Hidalgo, Morelos, la Corregidora, el abrazo de Acatempan, el Ejército Trigarante, etc. A lo que suceden más escenas de enfrentamientos entre insurgentes y realistas, así como la bandera mexicana alternándose con explosiones. Finalmente, la Independencia se consuma y parece que el país vive una modernización repentina, pues la siguiente imagen en verse en la pantalla es el ferrocarril. Es decir, la línea del tiempo entre las sociedades mesoamericanas y la modernidad liberal solo se ve interrumpida por los años de opresión y destrucción de la conquista y colonización que únicamente fueron superados con la unión del "pueblo mexicano" en la lucha por su independencia.

Otra iniciativa conmemorativa del ejecutivo federal que tuvo gran impacto mediático fue la ceremonia del traslado de los restos de los héroes de la patria, ${ }^{17}$ la cual fue especialmente criticada por la opinión pública. En esta ocasión, la historia oficial se difundió de una forma un tanto atípica, pues literalmente se pasearon los "huesos" de los héroes por toda la ciudad. ${ }^{18}$ El ejecutivo federal organizó para el 30 de mayo de 2010, fecha simbólica por cuanto es la fecha de nacimiento de Miguel Hidalgo, una ceremonia en la que los restos óseos fueron trasladados desde la Columna de la Independencia hasta el Museo Nacional de Historia, donde quedarían expuestos. La intención del gobierno federal con este acto fue, en palabras de Felipe Calderón, "identificar la identidad de los restos de nuestros héroes patrios"; y que finalmente permitió "corroborar plena e indubitablemente la identidad de los héroes que en el caso de alguno de ellos se había puesto en duda". ${ }^{19}$ Vemos, con ello, que el gobierno federal al tiempo que confirmaba la identidad de los héroes estaba reforzando uno de los puntos fijos de la historia oficial de México y, por ende, contribuyendo a reafirmar la identidad nacional mexicana.

Pero si hubo un momento en que las conmemoraciones alcanzaron su apoteosis fue el 15 y 16 de septiembre, durante las "fiestas patrias". La noche del día 15, antes de la recreación del Grito de Independencia por parte de Felipe Calderón, el gobierno federal organizó un gran desfile conmemorativo que recorrió el Paseo de la Reforma hasta llegar al Zócalo de la Ciudad de México. ${ }^{20}$ En esta

17 Citado en GOBIERNO FEDERAL, México 2010, op. cit., pp. 247-251; Citado en GOBIERNO FEDERAL, Reporte de las principales actividades, op. cit., p. 129; (Presidencia Felipe Calderón Hinojosa). (15 de agosto de 2019). Ceremonia de traslado de los restos de los héroes de la patria [Archivo de video]. Recuperado de: https://www.youtube.com/watch?v=OA8M6snClYg

18 Los restos óseos de los "padres de la patria" ya habían sido anteriormente objeto de distintas procesiones cívicas y religiosas, dado que el culto a los huesos, ropas y otros objetos de los héroes nacionales es una práctica vinculada con la religión católica, pero también a los pueblos prehispánicos. Si se desea ampliar la información sobre dicha cuestión: ZÁrATE, V., op. cit., pp. 90-91.

19 (Presidencia Felipe Calderón Hinojosa). (15 de agosto de 2019). Ceremonia de traslado de los restos de los héroes de la patria [Archivo de video]. Recuperado de: https://www.youtube.com/watch?v=OA8M6snClYg GOBIERNO FEDERAL, Bicentenario, la fiesta de todos: Celebración del 200 aniversario del inicio de la independencia nacional, México, Gobierno federal, 2010, pp. 8-17; Citado en GOBIERNO FEDERAL, 
iniciativa conmemorativa se puede ver claramente cómo tuvo lugar un desplazamiento en las formas en que la nación mexicana era representada, pues si durante el siglo anterior la nación era pensada como una entidad cultural e históricamente homogénea, durante el Bicentenario se pasa a una perspectiva multicultural que, en teoría, reconoce la pluralidad. ${ }^{21}$ De ahí que, en este desfile conmemorativo, las diversas regiones y etnias del país estuvieran representadas en los diferentes "cuadros plásticos" que recorrieron el Paseo de la Reforma, en los cuales se rememoraban los principales acontecimientos y actores de la Independencia y la Revolución. Se trató, pues, de hacer a todos los ciudadanos protagonistas de los dos momentos fundacionales de la nación mexicana.

No obstante, la iniciativa del gran desfile fue enormemente criticada por su falta de claridad en la representación del pasado, en el sentido de que los ciudadanos no supieron identificar las efemérides que se estaban celebrando, ${ }^{22}$ e incluso algunos críticos vieron en esta iniciativa una "afrenta a los sentimientos más profundos del pueblo", ${ }^{23}$ por la forma en que se había representado la historia mexicana en los diversos carros que compusieron la cabalgata. Sin embargo, estas críticas son algo exageradas, pues realmente el ejecutivo federal no hizo sino que desplegar en el desfile conmemorativo todos los tropos de la historia oficial, aunque fuera de forma poco acertada y, por esa razón, diera pie a la confusión en algunas ocasiones.

Buena muestra de todo ello fue que, a pesar de que los organizadores del espectáculo en el Zócalo buscaron asegurarse la comprensión del mensaje que se trataba de transmitir, mediante la difusión de explicaciones previas en los medios de comunicación; finalmente, los asistentes no supieron reconocer muchas de las figuras que compusieron el desfile, tal y como sucedió con la representación de Kukulkán en un globo de helio, el cual fue confundido por muchos espectadores con un dragón del año nuevo chino. ${ }^{24}$ Incluso el locutor que retransmitió el evento por televisión resaltó esta similitud: "me recuerda un poco a una suerte de feria china, como son los desfiles chinos con esos largos dragones, pues aquí tenemos a Kukulkán". 25

Una vez acabado el desfile, ya en el Zócalo, comenzó un espectáculo que fue la antesala del Grito, en el que se presentó la controvertida escultura de $E l$

Reporte de las principales actividades, op. cit., p. 141; (Presidencia Felipe Calderón Hinojosa). (16 de septiembre de 2010). Espectáculo en el Zócalo 200 años del Inicio de la Gesta de Independencia [Archivo de video]. Recuperado de: https://www.youtube.com/watch?v=DjXXM_SvyIc

21 Vargas Álvarez, S., Después del bicentenario politicas de la conmemoración, temporalidad y nación. Colombia y México, 2010, Bogotá, Editorial Universidad del Rosario, 2018, p. 3.

22 Citado en Garciadiego, J., op. cit., pp. 365-366.

23 AvILÉS, J. (18 de septiembre de 2010). “Aguafiestas patrias", La Jornada. Recuperado de: https://www.jornada. com.mx/2010/09/18/opinion/008o1pol

24 ZÁrate, V., "Haciendo patria. Conmemoración, memoria e historia oficial”, en Pani, E. y RodríGuez, A. (coord.): Centenarios. Conmemoraciones e historia oficial, México, D.F., El Colegio de México, Centro de Estudios Históricos, 2012, p. 91.

25 (Presidencia Felipe Calderón Hinojosa). (16 de septiembre de 2010). Espectáculo en el Zócalo 200 años del Inicio de la Gesta de Independencia [Archivo de video]. Recuperado de: https://www.youtube.com/ watch?v=DjXXM_SvyIc 
Coloso, ${ }^{26}$ anunciada por el historiador Greco Sotelo como una figura que representaba "el pueblo en armas, el pueblo insurrecto". ${ }^{27}$ La obra, por lo tanto, fue pensada para que tuviera un gran potencial simbólico, en la medida en que la rebelión popular ocupa un lugar de enorme relevancia dentro de la memoria histórica de los mexicanos y mexicanas, pues es vista como el principal motor del proceso de independencia. No obstante, finalmente resultó ser una de las iniciativas más controvertidas, pues muchos de los ciudadanos allí presentes y de los que siguieron el espectáculo por televisión, confundieron la figura con Emiliano Zapata, Joseph Stalin, Luis Donaldo Colosio, Vicente Fernández o Benjamín Argumedo, ${ }^{28}$ uno de los golpistas que derrocaron y asesinaron a Francisco I. Madero, considerado, por ello, un traidor a la patria.

Ante la polémica suscitada por la obra de El Coloso, la Secretaría de Educación Pública tuvo que desmentir públicamente a través de un comunicado de prensa que la escultura retratara a alguno de estos personajes, sino que era un "homenaje a los cientos de miles de mexicanos anónimos, casi todos campesinos pobres, que participaron en el movimiento insurgente". ${ }^{29}$ Sin embargo, las declaraciones realizadas por el escultor de la obra, Juan Carlos Canfield, vinieron a comprometer más aún al gobierno, pues reconoció que se había inspirado físicamente en Benjamín Argumedo, pero no ideológicamente. Aun así, muchos quisieron ver en ello una prueba de que el gobierno federal estaba enalteciendo a traidores de la patria como Argumedo, por lo que, al mismo tiempo, estaba deshonrando a los verdaderos héroes nacionales. ${ }^{30}$

Por otro lado, el último de los actos que se desarrolló en el marco de actividades del Grito fue la coreografía "Vuela México", ${ }^{31}$ en la que un grupo de acróbatas escenificaron una de las principales ideas difundidas por el ejecutivo en las conmemoraciones bicentenarias: la necesaria unión del pueblo mexicano. El espectáculo, de hecho, fue presentado por los locutores que lo retransmitieron como "una coreografía donde la no unificación de los criterios hace que [los acróbatas] no logren alcanzar el objetivo". ${ }^{32}$ Simbolizando con ello, una vez más, la necesaria conciliación de los mexicanos por el interés superior de la nación.

26 Citado en GOBIERNO FEDERAL, Bicentenario, la fiesta de todos, op. cit., p. 20.

27 (Presidencia Felipe Calderón Hinojosa). (16 de septiembre de 2010). Espectáculo en el Zócalo 200 años del Inicio de la Gesta de Independencia [Archivo de video]. Recuperado de: https://www.youtube.com/ watch?v=DjXXM_SvyIc

28 Citado en Vargas Állvares, S., op. cit., p. 89.

29 DíAz, A. (20 de septiembre de 2010). El Coloso no retrata ningún personaje particular: SEP. La Jornada. Recuperado de https://www.jornada.com.mx/2010/09/20/politica/015n1pol MarTínez CARBALLO, N., (22 de septiembre de 2010). Lamentable, discutir por "El Coloso": Lujambio. El Universal, p. 5; SEP: "Coloso" no es Vicente Fernández. (20 de septiembre de 2010). El Universal, p. 6.

30 Moctezuma Barragán, P., (17 de septiembre de 2010). Los festejos exaltan a contrarrevolucionario. $\mathrm{La}$ Jornada. Recuperado de: https://www.jornada.com.mx/2010/09/17/correo

31 Citado en GOBIERNO FEDERAL, Bicentenario, la fiesta de todos, op. cit., p. 21.

32 (Presidencia Felipe Calderón Hinojosa). (16 de septiembre de 2010). Espectáculo en el Zócalo 200 años del Inicio de la Gesta de Independencia [Archivo de video]. Recuperado de: https://www.youtube.com/watch? v=DjXXM_SvyIc 
Una vez acabado el espectáculo acrobático, finalmente llegó el momento de que el presidente de la República saliera al balcón del Palacio Nacional y recreara el Grito de Independencia: ${ }^{33}$ lanzó vivas a los héroes de la patria, ondeó la bandera mexicana y repicó una campana como, según recoge la tradición, hizo Miguel Hidalgo para llamar a la insurrección. Es, por lo tanto, un acto conmemorativo que por su estructura facilita que la historia sea usada como recurso político por parte del ejecutivo federal, pues el mandatario se presenta en dicha ceremonia como sucesor del "Padre de la Patria" y continuador del legado revolucionario. ${ }^{34}$

Otra cuestión que destacar de las conmemoraciones bicentenarias es el intenso uso que hizo el gobierno federal de los medios de comunicación, con el objetivo de popularizar las fiestas y darles publicidad. En este sentido, las iniciativas publicitarias desarrolladas para tal fin son un excelente documento para analizar la forma en que el ejecutivo presentó las conmemoraciones al gran público a través de los medios de comunicación, y no únicamente en actos solemnes. Por ello, los dos spots emitidos durante la presentación del programa de festejos, los cuales fueron posteriormente retransmitidos por televisión, son una fuente interesante de estudio, ya que a través de ellos el gobierno federal difundió, una vez más, el discurso nacionalista del sintagma "orgullosamente mexicanos". ${ }^{35}$ En ambos casos, el mensaje final que transmitían era: "Felicidades, cumples doscientos años de ser orgullosamente mexicano, y eso, hay que celebrarlo". ${ }^{36}$

Por otra parte, este afán que el ejecutivo federal demostró por popularizar las celebraciones del 2010 (pues buscó que las principales actividades conmemorativas se difundieran al máximo entre la población a través de los medios de comunicación) fue otro de los focos de crítica a las iniciativas gubernamentales. ${ }^{37}$ El seguimiento televisivo de algunos de los proyectos contribuyó, para algunos observadores, a la "balcanización del sentido profundo de la fecha", más aún cuando los propios presentadores de las cadenas de televisión que cubrieron los festejos demostraron no tener la preparación necesaria, pues "hicieron gala de una profunda ignorancia de la cultura nacional". ${ }^{38}$ En este sentido, los peligros de esta "espectacularización" de las conmemoraciones bicentenarias acabaron manifes-

33 Citado en GOBIERNO FEDERAL, México 2010, op. cit., pp. 43-78; (Presidencia Felipe Calderón Hinojosa). (16 de septiembre de 2010). Festejos por los 200 años del inicio de la Guerra de Independencia [Archivo de video]. Recuperado de: https://www.youtube.com/watch?v=LUNOoy1KFps

34 GonZÁlez Salinas, O.F., "Conmemoraciones históricas y lucha política. Las celebraciones de independencia en México, 1988-2014”, Bicentenario: Revista de Historia de Chile y América, vol. 16, núm. 1, 2017, p. 38.

35 "Orgullosamente mexicanos" es la etiqueta creada por el gobierno federal durante el Bicentenario de la Independencia para reforzar la identidad nacional. Ahora diríamos que fue el hashtag más identificativo y utilizado durante la coyuntura conmemorativa.

36 (Presidencia Felipe Calderón Hinojosa). (10 de febrero de 2010). Spot por el Bicentenario de la Independencia y Centenario de la Revolución mexicana [Archivo de video]. Recuperado de: https://www.youtube.com/ watch?v=gfqk96iBZO; (Presidencia Felipe Calderón Hinojosa). (10 de febrero de 2010). Spot por el Bicentenario de la Independencia y Centenario de la Revolución mexicana [Archivo de video]. Recuperado de https://www.youtube.com/watch?v=W74M_OvwkeQ

37 Citado en Carrillo Reveles, V., op. cit., p. $4 \overline{5}$.

38 Citado en Vargas Álvarez, S., op. cit., pp. 88-89. 
tándose: "reproducción de lugares comunes y estereotipos, exotización de sujetos y pueblos, banalización de la historia, falta de claridad y sentido en el mensaje, etc.". ${ }^{39}$ Así pues, las críticas fueron en la línea de cuestionar si la retransmisión televisiva de las celebraciones era la mejor forma de conmemorar la efeméride que da sentido a la existencia de la nación mexicana, ${ }^{40}$ en vez de haber aprovechado la coyuntura para ampliar el conocimiento histórico de la población y, con ello, reforzar la identidad nacional de los mexicanos y mexicanas.

Por último, me gustaría comentar una de las iniciativas conmemorativas más controvertidas del Bicentenario de la Independencia, incluso diría mayor que $\mathrm{El}$ Coloso, como fue el fallido proyecto de un Arco Bicentenario diseñado para la Ciudad de México por el ejecutivo federal. Requiere una mención especial porque desde que Felipe Calderón anunció su construcción, estuvo envuelto de polémicas, tanto por la cuestionada relación entre los jurados y algunos de los concursantes, como por el hecho de que el proyecto ganador fuera el diseño de una torre y no de un arco. ${ }^{41}$ Esto último se debió a que después de convocar a concurso a escultores y arquitectos, la intención de copiar el arco de San Luis Missouri de Estados Unidos "se vino abajo" y acabó ganando el proyecto Estela de Luz que, por si fuera poco, no se inauguró en el Año de la Patria, sino en 2012, con 15 meses de retraso. ${ }^{42}$ Aunque el mayor escándalo estuvo relacionado con el elevado costo que supuso para las arcas públicas, pues fue superior a los 1.304 millones de pesos (911 millones más de lo presupuestado en un principio). ${ }^{43}$ No obstante, el principal problema fue que para muchos críticos la Estela de Luz no cumplió la función para la que se esperó que fuera diseñada: no fijaba ninguna representación del pasado relacionada con la Independencia. Es más, el sobrenombre más conocido de este monumento fue el de "suavicrema", pues a muchos ciudadanos le recordaba a la galleta comercial con ese nombre. ${ }^{44}$ En definitiva, es evidente que la Estela de Luz no evocó ninguna imagen al observador que la relacionase con la historia mexicana y, menos aún, con la efeméride que se estaba conmemorando en 2010.

\section{Conclusiones}

Una vez analizadas las iniciativas conmemorativas que por su alcance y significado se han considerado más relevantes, pueden contestarse las cuestiones

\footnotetext{
39 Ibid., p. 121.

40 Citado en Granados, L.F., op. cit., p. 13.

41 GuedeA, V., "Iniciativas gubernamentales, académicas y privadas para la conmemoración del Bicentenario en México" en Gutman, M. y Molinos, R. (eds.), Construir Bicentenarios latinoamericanos en la era de la globalización, Buenos Aires, Infinito, 2012, p. 130.

42 MÁrquez, E., "Contra su bicentenario, ¿por qué ha fracasado el programa conmemorativo de Los Federales", Nexos, junio 2010, Recuperado de: https://www.nexos.com.mx/?p=13687; BaUtista, V., (6 de agosto de 2010). La Estela que no despunta. Excélsior, p. 8; SÁNCHEZ, L.C. (11 de agosto de 2010). La Estela no estará lista. Excélsior, p. 8.

43 Romero Puga, J.C., "Ejercicio de memoria", Letras Libres, marzo 2014, Recuperado de: https://letraslibres. com/revista-espana/ejercicio-de-memoria-2/

44 Vargas Álvarez, S., "Monumento Estela de Luz: disputas en torno a los usos públicos de la historia en el México del Bi/Centenario", Revista Tempo e Argumento, vol. 8, núm. 19, 2016, p. 149.
} 
inicialmente planteadas. La primera de ellas, recordemos, se preguntaba si el ejecutivo federal acabó por desplegar una memoria oficial de la Independencia más acorde con su proyecto conservador de nación y su concepción historiográfica e ideológica; o si finalmente se limitó a reproducir la misma que durante setenta años había legitimado al PRI en el poder. Con lo visto hasta ahora, todo parece apuntar a que acabó por darse más lo segundo que lo primero, pero con matices. Está claro que, por poner un ejemplo de lo analizado, el espectáculo audiovisual "200 años orgullosamente mexicanos" reproduce a la perfección la narrativa de corte liberal que durante décadas ha alimentado la historia oficial. Y es que el proyecto de nación conservador interpreta la Independencia como el final un proceso de crecimiento, a través del cual la nación mexicana se emancipa de España una vez que llega a su madurez; mientras que el proyecto liberal ve en ella una ruptura violenta con España. ${ }^{45} \mathrm{Y}$ en vista de las escenas del espectáculo que se han analizado anteriormente, lo que se muestra es la imagen de una nación mexicana que consiguió liberarse del yugo opresor de los españoles.

No obstante, puede matizarse esta afirmación, pues es destacable la elección del 10 de febrero como fecha de presentación del programa de festejos, así como la referencia de Calderón al abrazo de Acatempan. No puede ignorarse que, aunque fuera fugazmente, se estaba recordando un hecho histórico que no solo no sucedió en 1810, la fecha que se estaba conmemorando realmente, sino donde además Agustín de Iturbide tiene un protagonismo relevante, un personaje tradicionalmente denostado y considerado antipatriota por la historia de corte liberal. Sin embargo, su figura es reivindicada por los conservadores, para quienes es el verdadero autor de la Independencia, el auténtico Libertador, en el sentido de que fue él quien consiguió su consumación. Por lo tanto, la referencia de Calderón al abrazo entre Vicente Guerrero e Iturbide no debe pasar desapercibida.

Por otro lado, la segunda de las preguntas era si las iniciativas conmemorativas que se impulsaron tuvieron alguna utilidad pública, es decir, si sirvieron al supuesto objetivo del ejecutivo federal de alentar la unidad del pueblo mexicano. Parece que todo apunta a que no. No se puede negar que las fiestas fueron espectaculares y que se impulsaron no pocas actividades para celebrar el Bicentenario de la Independencia. Pero siendo realistas, iniciativas como El Coloso no representaron lo que, al parecer, se intentaba: no transmitió ningún mensaje que invitara a los mexicanos a sentirse orgullosos o buscar la conciliación. Del mismo modo, la Estela de Luz, a pesar del gran costo que supuso para el erario, tampoco dice nada no solo de la Independencia, sino que tampoco evoca ningún sentimiento al espectador que la relacione con el orgullo de ser mexicano o la unidad del pueblo. Por lo tanto, las intenciones iniciales del gobierno, perfectamente plasmadas en los discursos de Felipe Calderón, no tuvieron una contrapartida real en las diversas actividades conmemorativas que se desplegaron.

Finalmente, me parece interesante acabar con una reflexión que invite a comparar las conmemoraciones de 2010 con las actuales de 2021. Es curioso que

45 PÉrez Vejo, T., España en el debate público mexicano, 1836-1867. Aportaciones para una historia de la nación, México, El Colegio de México/INAH, 2008. 
cuando al PAN le tocó celebrar en 2010 la efeméride emancipadora, se ciñera más al relato tradicional de la Independencia que lo que actualmente está haciendo Andrés Manuel López Obrador. Desde hacía tiempo podía aventurarse que el actual ejecutivo federal no iba a estar cómodo celebrando el Bicentenario de la Consumación de la Independencia, y también podía intuirse que iba a decantarse por conmemorar a Vicente Guerrero antes que a Agustín Iturbide. Sin embargo, lo que nadie esperaba y ha causado gran estupefacción, es que en 2021 se acabaran celebrando los supuestos "700 años de la fundación de México-Tenochtitlan", en lo que puede interpretarse como una estrategia para eludir que la conmemoración de la consumación fuera el hito principal del 2021, lo cual no concordaría con su proyecto de nación y su concepción historiográfica. Un dato curioso que se relaciona con esta cuestión es que en el espectáculo "200 años orgullosamente mexicanos", analizado anteriormente, la fecha de fundación de la ciudad se sitúa en 1325, y no en 1321. Todo ello invita al lector a una reflexión final abierta, a sacar conclusiones relacionadas con el uso público del pasado nacional que tanto antes como ahora se realiza.

\section{Bibliografía}

\section{Fuentes consultadas}

Agullar, P., Políticas de la memoria y memorias de la política, Madrid, Alianza, 2008.

BrEÑA, R., "Historia compleja, festejo simple", en "Bicentenario de la Independencia ¿Qué celebramos?”, Nexos, septiembre 2009, Recuperado de https:// www.nexos.com.mx/?p=13272

Carrillo Reveles, V., "Graffiteando la historia: la conmemoración del Bicentenario de la Independencia de México”, Revista CCHEHS, núm. 2, 2010, pp. 33-54.

GARCIADIEGO, J., "La política de la historia: las conmemoraciones de 2010" en Pani, E. y Rodríguez, A. (coord.): Centenarios. Conmemoraciones e historia oficial, México, D.F., El Colegio de México, Centro de Estudios Históricos, 2012, pp. 333-369.

GOBIERNO FEDERAL, Bicentenario, la fiesta de todos: Celebración del 200 aniversario del inicio de la independencia nacional, México, Gobierno federal, 2010.

GOBIERNO FEDERAL, México 2010: crónica y memoria de las conmemoraciones del Bicentenario del Inicio de la Independencia Nacional y el Centenario del Inicio de la Revolución Mexicana, México, Presidencia de la República, Secretaría de Educación Pública, Consejo Nacional para la Cultura y las Artes, Instituto Nacional de Estudios Históricos de las Revoluciones de México, 2010.

GOBIERNO FEDERAL, Reporte de las principales actividades conmemorativas con motivo del Bicentenario del inicio de la Independencia Nacional y del 
centenario del inicio de la Revolución Mexicana, México, Secretaría de Educación Pública, Instituto Nacional de Estudios Históricos de las Revoluciones de México, Coordinación Ejecutiva Nacional de las Conmemoraciones, 2010.

González Salinas, O.F., “Conmemoraciones históricas y lucha política. Las celebraciones de independencia en México, 1988-2014", Bicentenario: Revista de Historia de Chile y América, vol. 16, núm. 1, 2017, pp. 37-66.

GRANADOS, L.F., "Independencia sin insurgentes. El bicentenario y la historiografía de nuestros días", Desacatos, núm. 34, 2010, pp. 11-26.

GuEDEA, V., "Iniciativas gubernamentales, académicas y privadas para la conmemoración del Bicentenario en México" en Gutman, M. y Molinos, R. (eds.), Construir Bicentenarios latinoamericanos en la era de la globalización, Buenos Aires, Infinito, 2012, pp. 125-146.

Hernández, T., Tras las huellas de la derecha. El Partido Acción Nacional, 1939-2000, México, Fondo de Cultura Económica, 2021.

Ibarra, A.C.; Ortiz, J. y TeCuAnhuey, A. (coord.), La consumación de la independencia. Nuevas interpretaciones, Xalapa, Universidad Veracruzana, El Colegio de Michoacán, UNAM, 2021.

Langston, J., "El dinosaurio que no murió: el PRI de México", en Servín, E. (eds.), Del nacionalismo al neoliberalismo, 1949-1994, México, Fondo de Cultura Económica, 2011.

Langston, J., De la hegemonía a la ignominia: el PRI de México, México, Centro de Investigación y Docencia Económicas, 2019.

LoAeza, S., Acción Nacional. El apetito y las responsabilidades del triunfo, México, El Colegio de México, 2010.

LoAezA, S., "La historia, la historia patria y la formación de un nuevo consenso nacional" en PANI, E. y RodríGuez, A. (coord.), Centenarios. Conmemoraciones e historia oficial, México, D.F., El Colegio de México, Centro de Estudios Históricos, 2012, pp. 381-408.

MÁrquez, E., "Contra su bicentenario, ¿por qué ha fracasado el programa conmemorativo de Los Federales", Nexos, junio 2010, Recuperado de https:// www.nexos.com.mx/?p=13687

MaYer, A. (coord.), México en tres momentos: 1810-1910-2010. Hacia la conmemoración del bicentenario de la Independencia y del centenario de la Revolución Mexicana. Retos y perspectivas, 2 vol., UNAM, 2007.

Medina PeñA, L., "Las dos historias patrias", en "Bicentenario de la Independencia ¿Qué celebramos?”, Nexos, septiembre 2009, Recuperado de https://www. nexos.com.mx/?p=13271

Moreno, R., "Nuestras ideas sobre la consumación. Recorrido historiográfico sobre el proceso de la consumación de la independencia de México", en TERÁN, M. y GAYOL, V. (eds.), La corona rota: identidades y representaciones en las independencias iberoamericanas, Castelló de la Plana, Universitat Jaume I, 2010.

PÉrez Vejo, T., España en el debate público mexicano, 1836-1867. Aportaciones para una historia de la nación, México, El Colegio de México/INAH, 2008. 
Perochena, C., "Tiempo, historia y política. Una reflexión comparativa sobre las conmemoraciones bicentenarias en México y Argentina", História da Historiografia, núm. 27, 2018, pp. 142-172.

Ríos GorDillo, C.A., "La memoria asediada: la disputa por el presente en la conmemoración del bicentenario", Secuencia, núm. 87, 2013, pp. 177-204.

Romero Puga, J.C., "Ejercicio de memoria", Letras Libres, marzo 2014, Recuperado de https://letraslibres.com/revista-espana/ejercicio-de-memoria-2/

Vargas Álvarez, S., "Monumento Estela de Luz: disputas en torno a los usos públicos de la historia en el México del Bi/Centenario", Revista Tempo e Argumento, vol. 8, núm. 19, 2016, pp. 130-161.

Vargas Álvarez, S., Después del bicentenario políticas de la conmemoración, temporalidad y nación. Colombia y México, 2010, Bogotá, Editorial Universidad del Rosario, 2018.

ZÁrate, V., "Haciendo patria. Conmemoración, memoria e historia oficial", en Pani, E. y Rodríguez, A. (coord.): Centenarios. Conmemoraciones e historia oficial, México, D.F., El Colegio de México, Centro de Estudios Históricos, 2012, pp. 77-121.

\section{Fuentes electrónicas}

(Presidencia Felipe Calderón Hinojosa). (10 de febrero de 2010). Programa de actividades del Bicentenario de la Independencia y del Centenario de la Revolución [Archivo de video]. Recuperado de https://www.youtube.com/ watch? $\mathrm{v}=\mathrm{uzFM} 7 \mathrm{xdM} 2 \mathrm{yU} \& \mathrm{t}=5 \mathrm{~s}$

(Presidencia Felipe Calderón Hinojosa). (10 de febrero de 2010). Programa de actividades del Bicentenario de la Independencia y del Centenario de la Revolución [Archivo de video]. Recuperado de https://www.youtube.com/ watch? $\mathrm{v}=$ YinX1BSVmFw

(Presidencia Felipe Calderón Hinojosa). (10 de febrero de 2010). Spot por el Bicentenario de la Independencia y Centenario de la Revolución mexicana [Archivo de video]. Recuperado de https://www.youtube.com/watch? $\mathrm{v}=$ gfqk96iBZOA

(Presidencia Felipe Calderón Hinojosa). (10 de febrero de 2010). Spot por el Bicentenario de la Independencia y Centenario de la Revolución mexicana [Archivo de video]. Recuperado de https://www.youtube.com/watch? $\mathrm{v}=$ W74M_OvwkeQ

(Presidencia Felipe Calderón Hinojosa). (6 de mayo de 2010). Video proyectado. 200 años de ser orgullosamente mexicanos [Archivo de video]. Recuperado de https://www.youtube.com/watch?v=11J99CZt3cI\&t=1277s

(Presidencia Felipe Calderón Hinojosa). (15 de agosto de 2019). Ceremonia de traslado de los restos de los héroes de la patria [Archivo de video]. Recuperado de https://www.youtube.com/watch?v=OA8M6snClYg

(Presidencia Felipe Calderón Hinojosa). (16 de septiembre de 2010). Festejos por los 200 años del inicio de la Guerra de Independencia [Archivo de video]. Recuperado de https:/www.youtube.com/watch?v=LUNOoy1KFps 
(Presidencia Felipe Calderón Hinojosa). (16 de septiembre de 2010). Espectáculo en el Zócalo 200 años del Inicio de la Gesta de Independencia [Archivo de video]. Recuperado de https://www.youtube.com/watch?v=DjXXM_SvyIc

\section{Prensa}

AvilÉs, J. “Aguafiestas patrias”, La Jornada,18 de septiembre de 2010. Recuperado de https://www.jornada.com.mx/2010/09/18/opinion/008o1pol

Bautista, V., "La Estela que no despunta", Excélsior, p. 8.6 de agosto de 2010. DíAz, A., "El Coloso no retrata ningún personaje particular: SEP", La Jornada, 20 de septiembre de 2010. Recuperado de https://www.jornada.com. mx/2010/09/20/politica/015n1pol

Martínez Carballo, N., "Lamentable, discutir por El Coloso. Lujambio", El Universal, 22 de septiembre 2010, p. 5.

Melgar, I., "Calderón pide superar las diferencias políticas", Excélsior, 11 de febrero de 2010, p. 4.

Moctezuma BarragÁN, P., "Los festejos exaltan a contrarrevolucionario", La Jornada, 17 de septiembre de 2010. Recuperado de https://www.jornada. com.mx/2010/09/17/correo

Ramos, J., "Convocan a festejar en unidad", El Universal, 11 de febrero de 2010, p. 22.

SÁnchEZ, L.C., "La Estela no estará lista”, Excélsior, 11 de agosto de 2010, p. 8. S.N., "Calderón apela a la hermandad", El Informador, 11 de febrero de 2010, p. 3-A.

S.N. “Coloso no es Vicente Fernández”, El Universal, 20 de agosto de 2010, p. 6. 